\title{
A NEW GENUS AND SPECIES OF CONIOPTERYGIDAE (NEUROPTERA) FROM NEW MEXICO*
}

\author{
BY Victor JoHNSON \\ Department of Entomology, University of Kentucky \\ Lexington, Kentucky 40506
}

A single male specimen of an undescribed genus of Coniopterygidae was collected in a blacklight trap in Las Cruces, New Mexico. The specimen keys out to the genus Helicoconis Enderlein of the subfamily Aleuropteryginae in Meinander's (1972) key, but genitalic studies show the need for a new generic designation. Because the genitalia of this new genus differ from all known genera of Coniopterygidae, it is difficult to make comparisons, but for descriptive purposes, the genitalia are compared to those of Helicoconis. The structures referred to here as ectoprocts are probably equivalent to the ectoprocts of Helicoconis but may represent other structures.

Bidesmida new genus

This genus so far contains only the type species and is apparently most closely related to Helicoconis, which is widely distributed in the Holarctic Region and Africa.

Male-Head capsule with unsclerotized area on frons, including antennal sockets. Maxillary and labial palps long and slender; last segment of palps only slightly broader than preceding segments. Scape and pedicel about twice as long as broad.

Forewing with $\mathrm{R} 4+5$ superficially resembling an anterior branch of $M$. $M$ bearing several small setae. Two in the middle of the wing only slightly more prominent than the rest. Bases of setae not enlarged and $M$ not appreciably narrowed between setae.

Plicaturae present on abdominal segments 3-7.

Male genitalia apparently formed from elements of eighth, ninth and tenth segments. Ninth segment forming a closed ring.

*This paper (No. 76-7-70) is published with the permission of the Director of the Kentucky Agricultural Experiment Station and is based on research performed in partial fulfillment of the requirements for the PH.D. degree in Entomology.

Manuscript received by the eattor August 20, 1976. 
Eighth segment represented by a sclerotized plate forming the of M. M. bearing several small setae. Two in the middle of the ectoprocts apparently represent elements of tenth segment and perhaps part of the ninth as well (Meinander 1972).

Type-species: Bidesmida morrisoni n. sp.

Bidesmida is similar to Helicoconis in wing venation and in having plicaturae on abdominal segments 3-7. Bidesmida differs from Helicoconis in having the eighth sternum strongly sclerotized and forming the venter of the genital capsule, the ectoprocts being fused distally, and the parameres being fused with the ectoprocts.

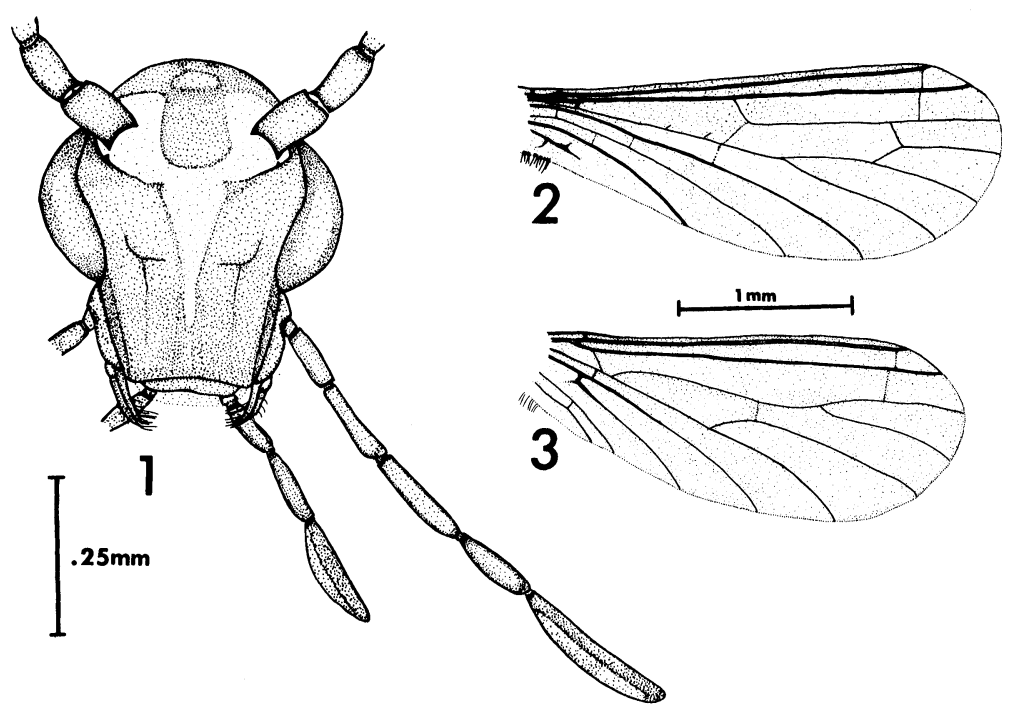

Figures 1-3. Bidesmida morrisoni, n.sp. Fig. 1, anterior view of head. Fig. 2 , front wing. Fig. 3, hind wing.

Bidesmida morrisoni new species

Male-Head capsule (Fig. 1) with large unsclerotized area on frons, including antennal sockets, and extending ventrally in a tapering tongue to near clypeus. A sclerotized area extending down from vertex into this unsclerotized area. Eyes large. Palpi long and slender. Last segment of palpi only slightly broader than 
preceding segments. Antennae 26 segmented. Scape and pedicel about twice as long as broad. Second and third flagellar segments smallest of antennae, one and one-half times as long as broad. Remaining flagellar segments larger, twice as long as broad except terminal segment three times as long as broad.
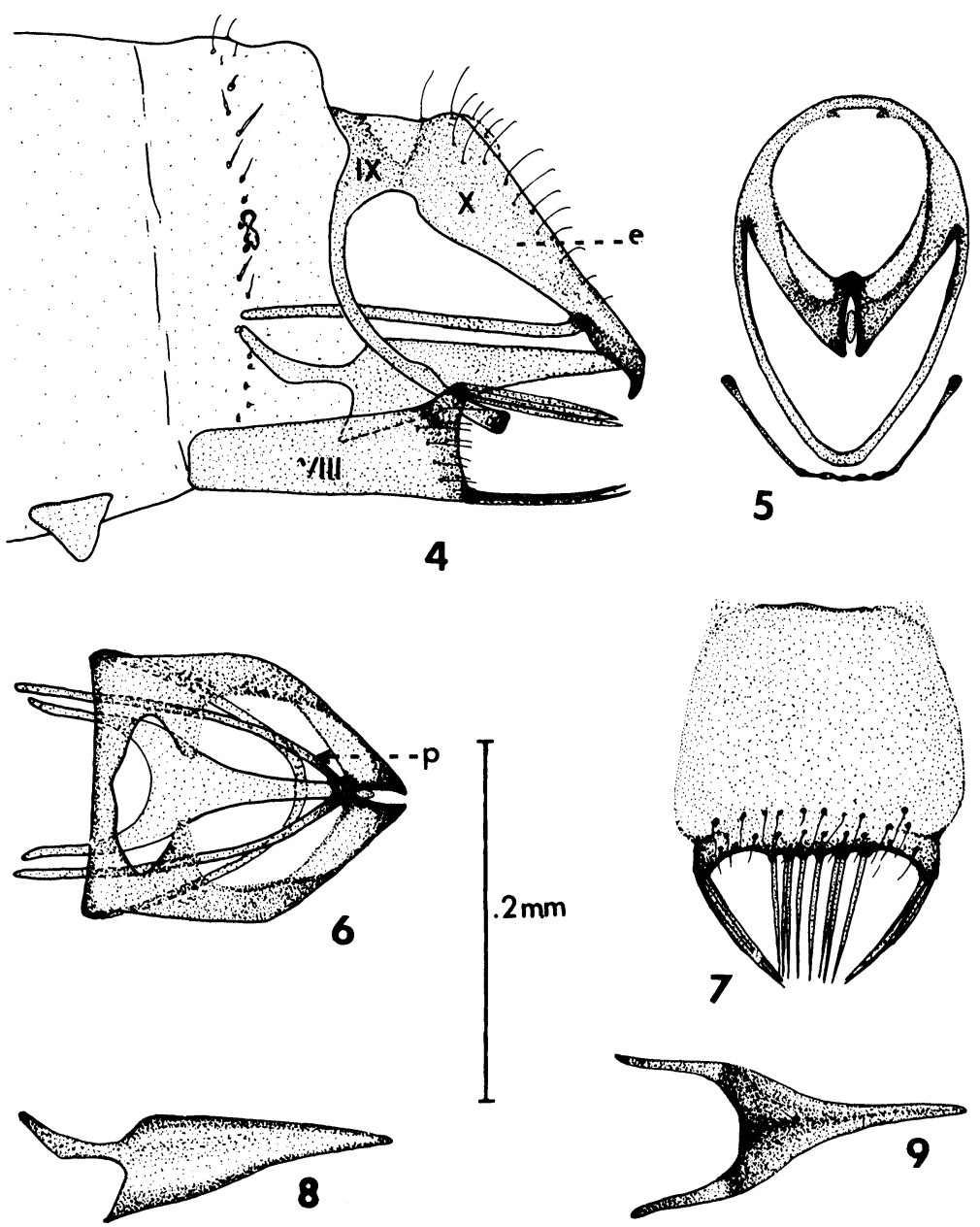

Figures 4-9. Bidesmida morrisoni, n.sp. Fig. 4, lateral view of genitalia $(\mathrm{e}=$ ectoprocts). Fig. 5, caudal view of genitalia $(\mathrm{p}=$ parameres). Fig. 6 , dorsal view of genitalia. Fig. 7, ventral view of eighth sternum. Fig. 8, lateral view of penis. Fig. 9, ventral view of penis. 
Wings(Figs. 2-3) hyaline without dark spots or pattern. R4+5 of forewing superficially resembling an anterior branch of $\mathbf{M}$. Forewing $2.7 \mathrm{~mm}$ long and hindwing $2.3 \mathrm{~mm}$ long. Both wings about $0.8 \mathrm{~mm}$ wide at widest part.

Male genitalia (Figs. 4-9) ninth segment forming a closed ring becoming a narrow band ventrally, fused with ectoprocts dorsally. A weakly sclerotized dorsal area may indicate limits between ninth segment and ectoprocts. Ectoprocts extending posteriorly with distal ends fused medially. Parameres long, fused with ectoprocts posteriorly. Penis formed of two rods fused posteriorly to form a tube. No hypandrium or styli evident. Eighth sternum strongly sclerotized and forming ventral portion of genital capsule. A row of heavy spines along posterior margin of eighth sternum and a group of several large spines on postero-lateral angles. An additional double row of smaller spines just anterior to posterior margin.

Holotype male: Las Cruces, New Mexico, blacklight trap, November 30, 1975, W. P. Morrison. Holotype deposited in USNM.

Female and immature stages unknown.

\section{Literature Cited}

Meinander, M.

1972. A revision of the family Coniopterygidac. Acta Zool. Fennica. 136: 1-357. 

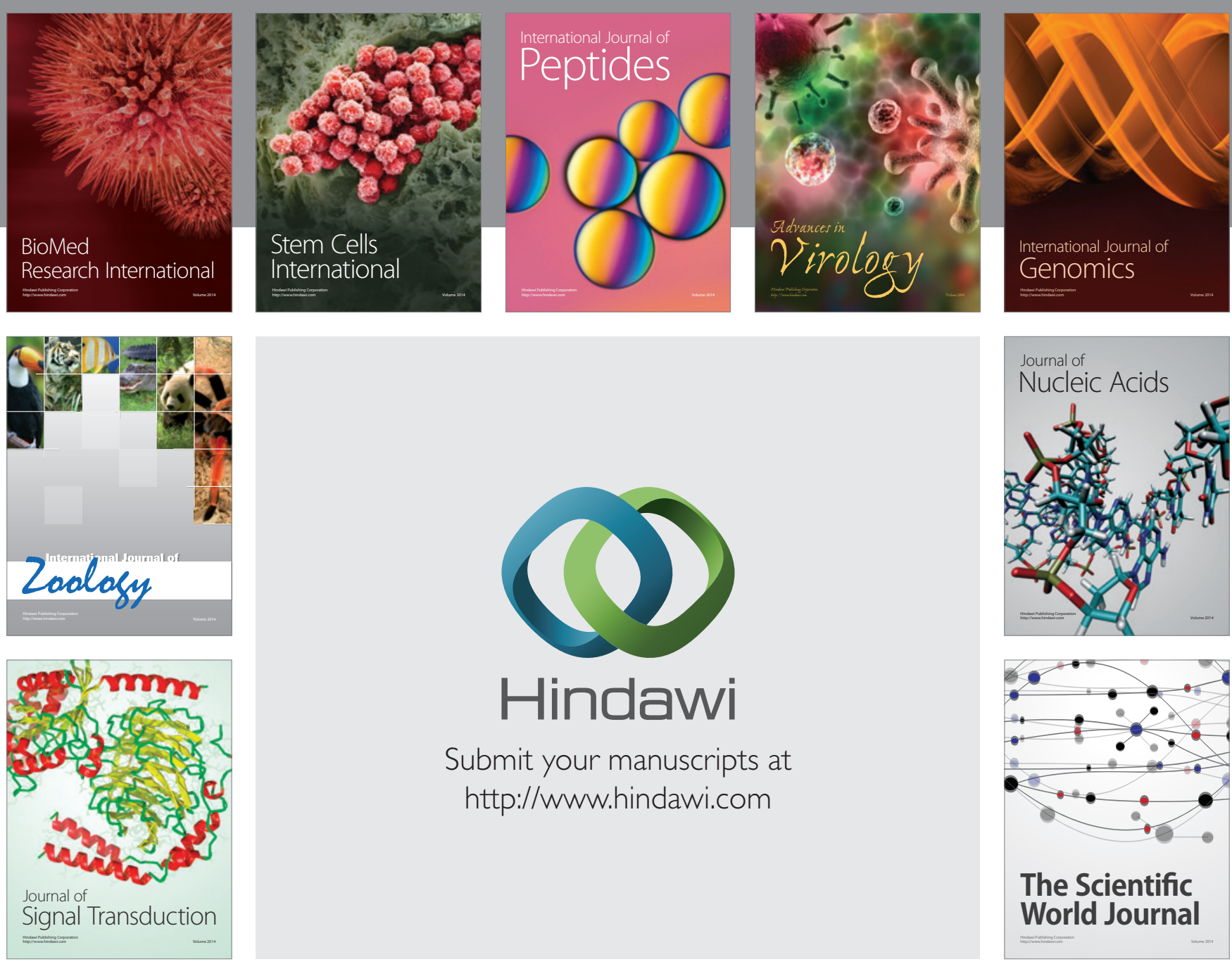

Submit your manuscripts at

http://www.hindawi.com
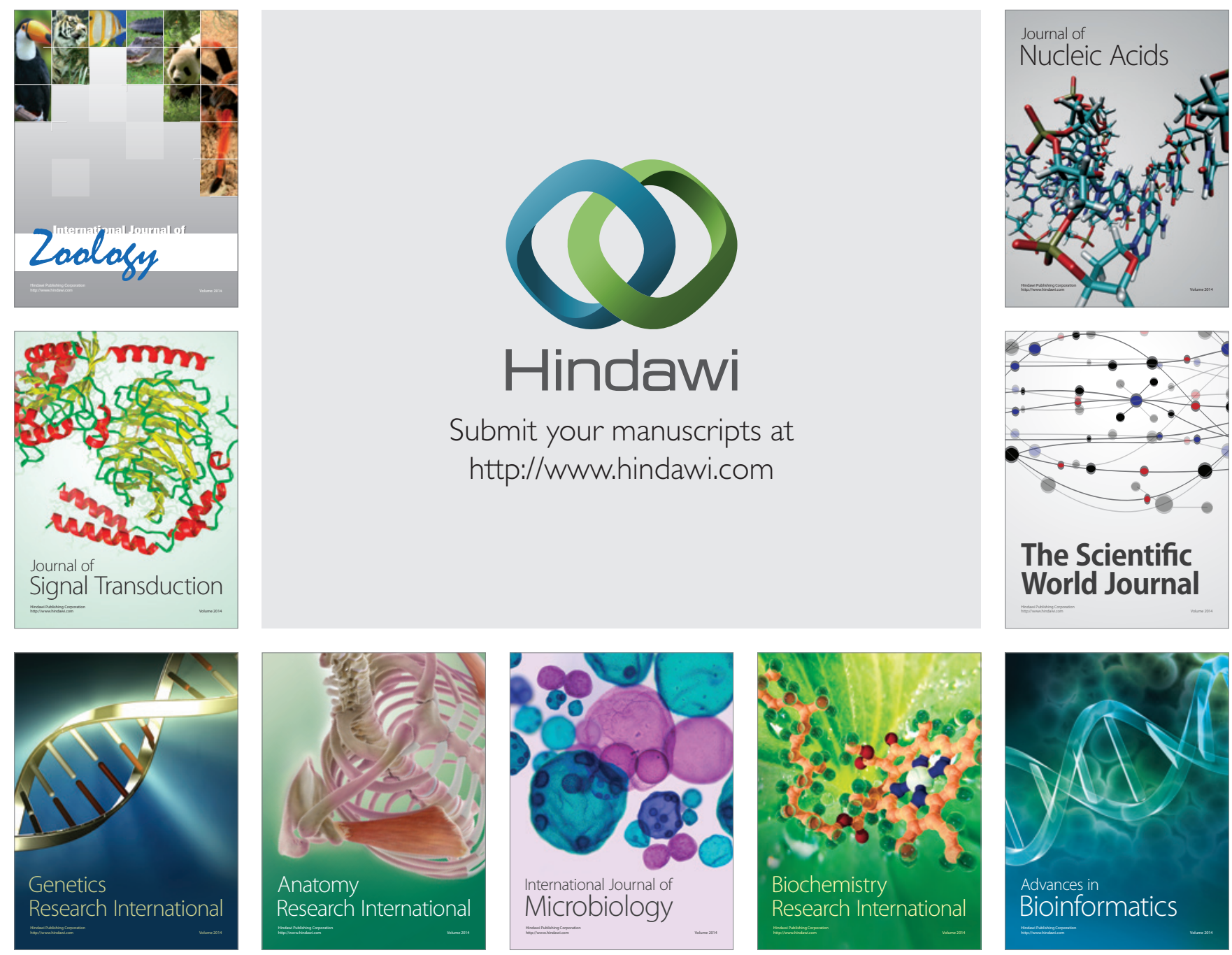

The Scientific World Journal
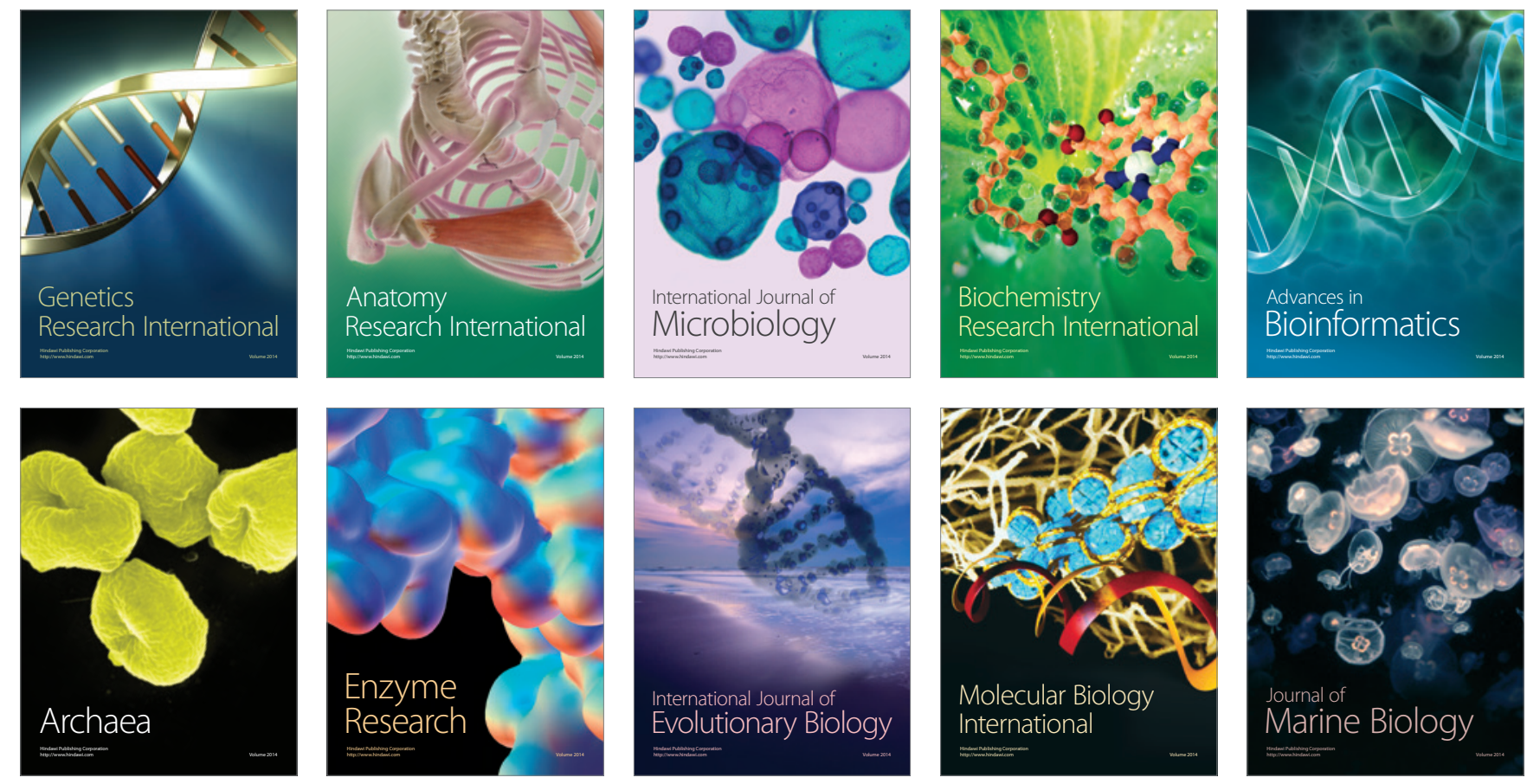